\title{
Success4Life: An aspirational programme for looked after children
}

\author{
Emma Lewis, University of Manchester \\ Emma Williams, University of Manchester \\ Penny Lewis, University of Manchester \\ David Allison, University of Manchester (corresponding author) \\ Email: david.allison@manchester.ac.uk
}

DOI: http://dx.doi.org/10.5456/WPLL.17.4.116

\begin{abstract}
Looked after children are a grossly under-represented group in Higher Education, with only 7\% of care leavers entering HE. 'Success4Life' is a highintensity widening participation project delivered by the University of Manchester for high school pupils in local authority care. Although the theme of Higher Education runs through the project, the Success4Life programme has a particular focus on developing lifelong skills in attendees and the application of those skills to education and careers more broadly. Working alongside positive role models, the project seeks to develop positive self-image, confidence, presentation and teamwork skills through a variety of group work and themed sessions. Feedback from post-programme questionnaires was extremely positive. Most attendees reported an increased desire to stay in education post-16 and to apply to University, and the development of key skills such as self-confidence.
\end{abstract}

\section{Introduction}

The overall aim of most Widening Participation (WP) programmes is to encourage people from underprivileged backgrounds, who have the potential and desire, to enter into Higher Education (HE) (Department for Business, Innovation and Skills, 2015; Bridger et al., 2012). Generally speaking, WP programmes are particularly focused on targeting young people who are under-represented in $\mathrm{HE}$, for example, those from lower socio-economic backgrounds, ethnic minorities, disabled people and looked after children (Department of Education and Skills, 2013). Programmes aim to encourage people from these groups not only to access HE, but where appropriate to apply to the more selective universities and competitive courses across the country. This can be a particular problem for professional subjects such as medicine, dentistry and pharmacy (Greenhalgh et al 2004; Swain 2006) where many young learners do not consider themselves to be of the right type for courses leading to these 'high status' professions. Although data suggests that those young learners from underprivileged backgrounds who do enter university are just as likely to 
succeed as those from privileged backgrounds, they often require extensive nurturing and support to make it through to graduation (Attwood, 2008).

A 'looked after child' is defined as a young person under 16 who, for various reasons, is 'looked after' by their local authority (e.g. council / state) for 3 months or more. Children may become a looked after child for many different reasons, including situations where the local authority has taken on the parental responsibility for them, where the child is under criminal law supervision, or where they are under a court-ordered secure remand. If a child is an unaccompanied asylum seeker, they are also viewed as a looked after child (National Network for the Education of Care Leavers, 2013). In the UK there are approximately 65,000 looked after children, the majority of whom will have experienced significant emotional trauma and disruption to both home and educational life. Unsurprisingly, academic achievement is generally much lower for this group of young learners, a trend that starts in the early years of education and continues throughout their lives (Hart and Williams, 2008). Consequently, only 7\% of looked after children enter $\mathrm{HE}$ at the age of 18 , compared to approximately $40 \%$ of young people nationally (UCAS, 2013)

The factors which affect academic attainment and uptake into HE for looked after children do vary from individual to individual, but can include a lack of personal, emotional and practical support, coupled with a lack of continuity of care. Fundamentally, looked after children often need additional support due to the absence of a family system (Care Leaver's Association, 2012), but this targeted support is an area that is frequently under-valued and is often combined with provision for all disadvantaged young people (APPG, 2012). Any advice and support that universities can provide on all aspects of student life will therefore be of benefit to these young learners. Equity of access to $\mathrm{HE}$ is one of the University of Manchester's core values, and much of its widening participation and outreach work involves engagement with under-represented groups in local boroughs. As part of an overall programme of activities aimed at addressing inequity and to support the progression of a talented cohort of young people currently under-represented in HE, a number of schemes have been introduced. These include 'Mentoring Plus' (Bates et al, 2007), 'Pharmacy in Primary Schools' (Allison and Moore, 2007) and the 'Success4Life' programme, which specifically targets and supports looked after children.

Success4Life is a widening participation programme with a difference: whilst the theme of Higher Education runs through the project, there is a particular focus on the transferable lifelong skills attendees develop and the way in which these will help the young learners throughout their education and careers more broadly. The programme seeks to develop positive selfimage, confidence, presentation and teamwork skills, through a range of group work activities and themed sessions. Pupils work alongside positive role models (current University students, some of whom are care experienced) and University staff. This article describes the involvement and experiences of looked after children on the Success4Life programme. It reflects on how the information gained may be used to positively enhance 
perceptions, to raise pupil aspiration, to provide reassurances that targeted support will be available during their time at university and most importantly to ensure that attendees can imagine themselves at University in the future.

\section{The Success4Life Programme}

Success4Life is a skill- and aspiration-based programme targeting Key Stage $3 \& 4$ High School pupils (11-16 year olds) in local authority care. Due to the sporadic engagement with looked after young people at general WP/outreach events, this project was designed to engage specifically with these pupils.

The programme was launched in 2012 and to date approximately 70 pupils have taken part from years 7-11. Feedback from pupils, social workers and carers has been consistently positive. Indeed, some pupils have enjoyed the programme so much that they returned for a second, or on two occasions, a third year! The programme was originally designed to work with a very small group of targeted learners, on a very intense scale. The minimum group size is five, and the maximum around fifteen, although this was open to change' The high ration of staff / ambassadors to pupils (around 2 staff members for every 1 learner) ensures that every child receives sufficient attention, and the familiarity helps to develop a trusting, working relationship. Pupils are nominated to take part in the programme, either by their designated teacher in school, or by their social worker. Demand for places on the programme has grown over the years with the most recent project (Autumn 2014) receiving 19 nominations, which were accommodated with no detriment to the quality of the programme. As well as demonstrating academic potential and ability, some of the reasons that teachers gave for nominating their pupils included "to build confidence and self-esteem", "to meet new people" and "to raise aspirations". In a preproject questionnaire developed to include a combination of Likert-scale ratings (1-5) and qualitative (free text) responses, $100 \%$ of the young learners completed this stating that their reasons for wanting to participate were "to learn more about university", "to learn new things", "to meet new people" and "to graduate from Success4Life". These provided us with a strong baseline and subsequently became the working objectives of the Success4Life programme.

Before launching, the University of Manchester sought advice from tutors and current students on the University's Clinical Psychology programme, who helped in the planning of the project and attended sessions on behaviour management and pastoral support. In addition, a strong working relationship was developed with Children's Services at Manchester City Council, where colleagues were able to advise on the needs of the young learners. The approach that was adopted was of a personalized nature, choosing activities that would help attendees develop 
their soft skills as well as activities that gently introduced the concept of Higher Education.

Each session took place from $4-6 \mathrm{pm}$ on campus on a weekly basis for a period of ten weeks. Sessions were deliberately timed in order not to disrupt the normal school day. Taxis to and from the sessions were provided and paid for by the University. The first 30 minutes of each session was quite informal, providing a chance to catch up and for the learners to get to know the staff and each other better. Significantly, sessions were informal and non-compulsory. Learners were allowed to create their own set of ground rules at the beginning of the project, as well as consequences should these rules be broken by either pupils or staff.

Each session began with ice breakers delivered by different members of staff. The body of the session would then be dedicated to a different generic theme each week, such as teamworking skills, building self-confidence, or communication skills, delivered through a variety of hands-on group work activities, games and self-reflection. The activities ranged from learning sign language to bhangra dancing. The theme-based activities were short and interactive, to maintain the attention and concentration of the learners and were usually delivered by widening participation staff. Occasionally, external visitors were invited to lead parts of sessions including representatives from RECLAIM (a Manchester-based leadership and mentoring project), Barnardos (a British charity providing care for vulnerable children and young people) and Manchester City Council, the latter explicitly focussing on what local authority support is available and what rights a young person in care has. There was also an important and powerful session where care leavers from the University of Manchester came in and spoke about their respective educational / career pathways. This was a highly successful session and one that will be extended in future, as these advocates were ideal role models. They were able to inspire the young learners and provide an optimism grounded in reality. In addition, some activities focussed specifically on University life. These included a campus tour, interviewing current students, learning about a specific career and preparing for graduation.

The final session included a graduation ceremony for the young learners which teachers, social workers, carers and parents were invited to attend. It was deemed essential to engage carers and key workers with the programme, not only to help sustain pupil engagement, but also to provide these adults with knowledge about HE and care leaver support. The graduation ceremony provided an ideal opportunity to showcase the young learners' achievements and for them to comment on aspects of the programme that had meant a lot to them. 


\section{Pharmacy as a Career: an example of career specific workshop activity}

A new venture for the 2014 project was to introduce a specific academicthemed activity, in order to illustrate some of the teaching and learning methods used by the university. Pharmacy was selected, because not only is it a very popular course at the university, but also because it is considered a professional subject with an almost guaranteed job available following graduation.

The aims of the pharmacy element were: to introduce pharmacy as a potential career option and to incorporate different teaching styles as used by undergraduates on the Masters in Pharmacy (MPharm) degree programme. The content was also structured around the Key Stage three syllabus, but with a pharmacy slant. The first session focussed on the benefits and practicalities of a higher level education, and ensured that the young learners were aware of the support on offer at the university for students from a care background. The young learners were split into small groups and were able to discuss with the undergraduate ambassadors some of the myths and realities of university life. After a discussion on what softskills were essential for various jobs, the session ended with an excellent but rather messy teamwork activity whereby each group was tasked with building the tallest, and most stable, tower made out of spaghetti and marshmallows. This proved to be an excellent ice-breaker (see figure 1).

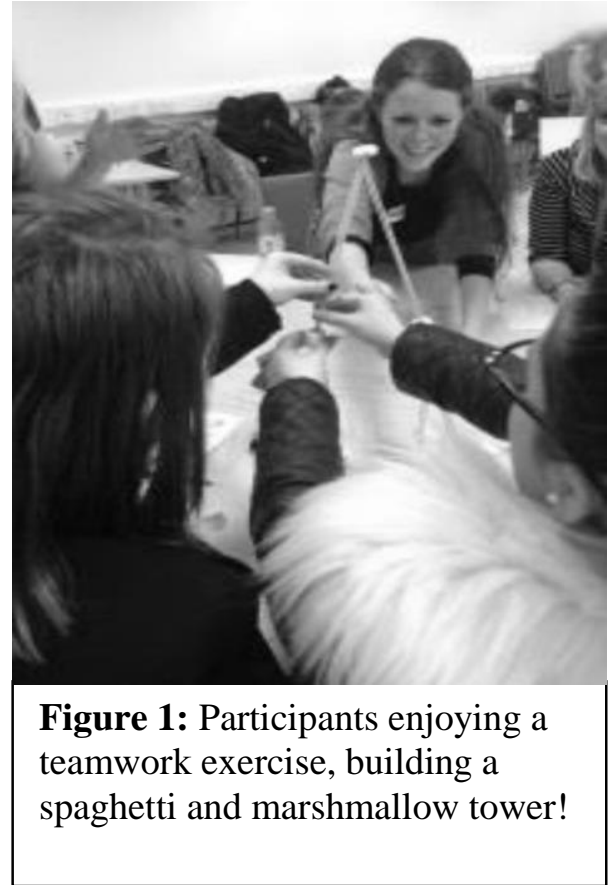

The second session began with a brief introduction to the pharmacy profession and what the requirements are to study pharmacy. The group of 17 young learners then split into four groups to look in detail at some common clinical conditions (diabetes, asthma, smokers lung, high blood pressure).Using case study material, the learners had to decide on what medical / clinical information a pharmacist would provide as well as select, and prescribe, the correct medication from a varied collection. The activity 
was hands-on, as participants were also able to take blood pressure readings, use Clini-stix to test for diabetes (in some fictitious blood!) and examine a range of inhalers (Figure 2). Following a short snack-break, the workshop resumed by looking at the importance of hand-washing, using fluorescent particles to mimic microorganisms. Although a tried and tested favourite activity for outreach events (Allison and McGuinness 2011), participants were again quite surprised at how thoroughly their hands had to be washed in order to remove all transient 'bugs'.

Although behaviour was at times challenging (the pupils ranged from loud and disruptive to fiercely shy and self-conscious), all of the participants engaged fully with the pharmacy activities with some pupils showing a genuine interest in the topic. Moreover, the workshop also provided an excellent opportunity for the undergraduate ambassadors' helpers to experience real-life issues! On the basis of feedback received from the participants (see below), the workshop was deemed to be a success. If nothing else, the workshop clearly demonstrated to the young learners that university can provide a fun learning environment, and that they too have the right to attend should they choose to do so.

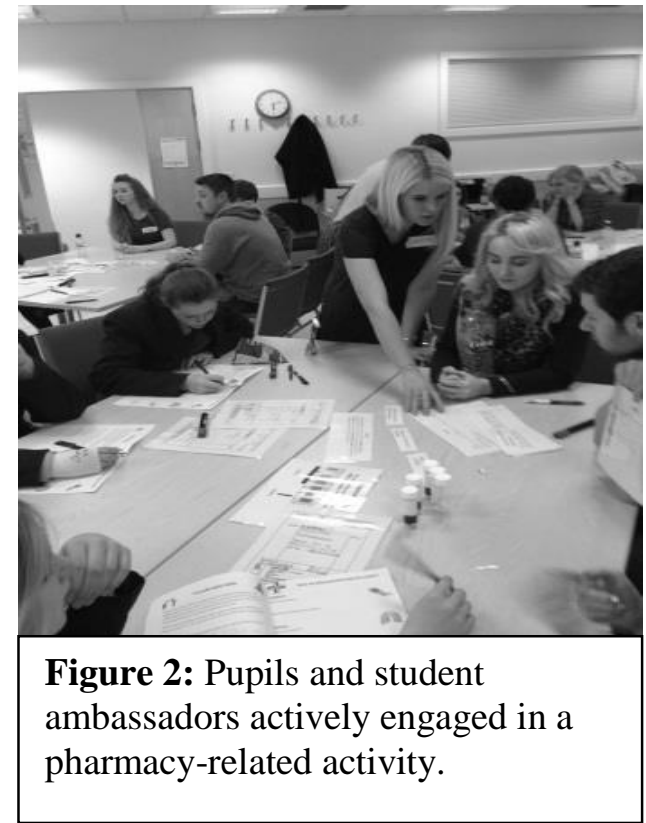

\section{Feedback and evaluation}

Evaluation of the Success4Life programme occurred in two phases. Firstly, short feedback questionnaires were completed by both the young learners and their guests at the graduation ceremony. There were 70 participants in the programme, all of whom completed a pre-project questionnaire, and 63 of whom completed a questionnaire after taking part.

Secondly, a focus group was held with six of the looked after children, who met approximately one month after the end of the last project. 
The pre- and post-project questionnaires contained similar questions, so that organisers could gauge what impact the programme had had on the attendees. Both sets of questionnaires contained a mixture of Likert-scale ratings (1-5) and qualitative (free text) responses. Pre-project evaluations were used to measure the attitudes of the young learners to higher education, their skill set and their expectations of their own self-growth and confidence through the experience. Responses were also used to partly inform the content of the workshops.

Summarised feedback collated over the past 4 years from pupils, social workers and carers was consistently positive. Attendees reported an increased desire to stay in education after the age of 16 following the Staterun General Certificate of Secondary Education exams (76\% pre-project, $93 \%$ post-project), an increased intention to apply to university (85\% preproject, 97\% post-project) as well as a greater awareness of university courses and options available to them (44\% pre-project, $63 \%$ post-project).

The young learners that attended the programme were nominated by their class teachers or social workers, and one reason they were identified was their academic potential. Thus, although $85 \%$ of those completing the preproject evaluation stated an interest in applying to University, one disabling feature that virtually all of the nominated young learners shared was the difficulty that they had believing in their own ability and potential. Due to the teacher nominations, the learners felt there was an expectation on them to consider university, rather than a genuine belief in their own ability to attend. Hence, a key aim of the programme was to build self-confidence in the young people so that they would feel able to make the most of opportunities open to them. End-of-programme evaluations clearly showed that the participants demonstrated increased confidence and felt more comfortable taking part in discussions and group activities. Examples of some favourable comments made by the participants are shown in Table 1. No negative comments were received.

\section{Table 1: Participants feedback comments about} Success4Life programme

- "Success4Life is great...l love going"

- "I have been going to Success4Life at the university...it has really helped me to feel more confident. Last year I was dreading my English presentation, this year has been much easier because I have learned to express my views in front of others".

- "I went to Success4Life at the University, it was good because I could talk to other children who are also in care and get to know them as friends. It was good to talk to others who have shared similar experiences".

- "I just want to say that this project has made me realise that just because I have a social worker doesn't mean I'm any different from anyone else". 
The focus group used qualitative methods to investigate emerging themes for the young people from experiencing Success4Life, what they enjoyed from the sessions and why some of them kept returning to repeat the programme. Some of the participants found speaking in the group context challenging, so to facilitate discussion the group was broken down to pairs, one pupil and one staff member, with the adults leading the discussion. The young people contributed to group feedback when they felt safe and ready to express their opinions, all of which was extremely positive, citing examples such as an increase in self-belief, discipline and confidence, having an open mind, developing communication and presenting skills and learning to be more considerate to others as some of the shared, positive learning experiences. One participant commented that "I just want to say that this project has made me realise that just because I have a social worker doesn't mean I'm any different from anyone else", a very positive realisation that was subsequently shared by the other participants.

Trust was often an issue for the young people and during the pair-work discussions one person stated that despite attending all the sessions: "I don't trust anyone, it's really hard for me to meet people. I don't feel safe". This was despite seeming to get along with everyone and enjoying the sessions. This suggests that if a large part of the young people's time is taken up with establishing who they can trust, and feeling safe enough to share, they may not get as far with reflecting on the activities and reflecting on their own growth. There was a feeling that the sessions could have been slightly longer, with seven of the group, including staff, agreeing that they were too short. This is one aspect that will be taken into consideration for future projects.

The pharmacy activity was also deemed to be a success, with $100 \%$ stating that they liked it a lot, and the majority of respondents describing the activities as "fun (100\%)", educational (89\%)", "helpful" and "useful" (79\% each). Many of the children seemed to enjoy the second part of the workshop the most, with $44 \%$ citing the hand washing activity as their favourite. When asked what would make the workshop better, $56 \%$ stated "nothing" with one pupil additionally commenting "it was brilliant anyway". The aim of the workshop was to provide the young learners with information that they might use in the future in regards to Higher Education (and in particular, for a potential career in pharmacy), in a setting, outside of the classroom, that made the topics and delivery of greater interest and value (Department for Business Innovation and Skills, 2014; Ofsted, 2008). Based on the success of the Pharmacy programme, future projects will look to incorporate a wider range of subject and career specific activities.

\section{Concluding remarks}

The educational attainment of looked after children continues to be considerably worse than the attainment of the rest of the school-age population. Consequently, pupils from care backgrounds are less likely to apply to university at all, let alone for a professional subject such as 
pharmacy. Moreover, widening access initiatives to increase applications from and subsequent retention in such individuals has had mixed success. One reason for this might be that most widening access programmes are fairly generic in nature and do not focus exclusively on the needs of a looked after child. Motivating young people in care to value their education is a large factor in the Success4Life structure. Experiencing a university campus through a campus tour and the behind-the-scenes Student Union tour at University of Manchester were all effective in promoting higher education, and made an impact through engaging with these young people. It is in this context that Success4Life provides an intervention into the lives of the young people, making a positive and hopefully, lifelong difference to individual behaviours.

The extremely positive feedback about this programme suggests that the space and time provided by Success4Life is a chance for these vulnerable young learners to change their ways of thinking around behaviour, restructuring modes of expression and even carrying realisations over into their behaviour in other contexts. It lays a foundation for a process of selfregulation, taking responsibility for their own behaviour and understanding there are consequences. The freedom element of the sessions was derived from the young people contributing to the sessions. At the first session, they were asked what they wanted from Success4Life, and this attitude of giving them activities that would engage them was effective in keeping group morale high and interest in the sessions consistent.

The project provides young people, who often face stereotyping and/or stigma of being a looked after child at home or at school, the chance to feel successful at something: the importance of this on their self-esteem was evident at the graduation. Having the time separate to school and home life to both socialise and learn was beneficial, and the ten week duration of the project enabled trust to be built. It was important that the role of the facilitating adults was seen as working with them willingly, to differentiate from their teachers who were 'just there as a teacher'. At Success4Life, adults invest their time and energy in the young people independent of the system. This enables the young people to begin reaching out, developing the confidence to step into new situations such as the graduation presentation with which Success4Life culminates.

More creative, interactive ways of learning were appreciated by pupils on the programme. This was an integral part of the project, introducing them to activities and experiences they might not have encountered before. On the basis of the successful pharmacy-specific workshop, there is also the potential to link the sessions more strongly with the type of skills that they have learnt that they can use in the future. This could be facilitated by including a stronger use of role models who are care-experienced who could become a more regular part of the sessions, but their use should be spread out so that it is not overwhelming.

Demand for Success4Life has steadily increased since the first programme in 2012. Key aspects to the success of the programme have been 
the one-to-one interaction with facilitators and the intensity of the workshops in an emotionally secure and safe environment, encouraging emotional awareness and self-regulation, impulse control, optimism, empathy and self-efficacy in the young learners. Any increase in participant numbers beyond twenty would be of concern, as the intimacy of the programme would be lost. Moreover, time constraints on the existing staff delivering the programme would exclude running multiple sessions. Similarly, whilst it would be good to take the programme 'on the road' to allow areas of Greater Manchester less geographically accessible to the University to take part in activities delivered by University staff and students, this would be limited by staff availability. On a more positive note however, one suggestion would be to have more individuals come in and speak about their experiences and pathways from different perspectives, and subjects that might be of interest to the young people and tie into greater ideas about their futures. These would be role models not just with a university background, but from all walks of life. This may encourage growth and resilience, in particular, optimism that is grounded in reality.

\section{Acknowledgments}

Sincere thanks to all who participated in the Success4Life programme, including all pupils, teachers and key workers, university staff and last but by no means least, all of the wonderful and dedicated undergraduate ambassadors. 


\section{References}

Allison, D.G. \& McGuinness, E. (2011) 'How clean are your hands? Raising Children's awareness of Microbes', Pharmaceutical Journal, 287: 329.

Allison, D. and Moore, J.E. (2007) 'Involve them while they're young promoting pharmacy in primary schools', Pharmaceutical Journal, 279: 234-235.

All Party Parliamentary Group for Looked After Children and Care Leavers. (2012) 'Education Matters in Care'. [ONLINE]. Available at: http://www.thewhocarestrust.org.uk/data/files/Education Matters in Care September_2012.pdf (Accessed 18 May 2015).

Attwood, K. (2008) 'School grades are key to University achievement', Times Higher Education Supplement, 19 June 2008, [ONLINE]. Available at: http://www.timeshighereducation.co.uk/story.asp?sectioncode=26\&storyco $\mathrm{de}=402432 \& \mathrm{c}=2$.

Bates, S., Gonzalez, S., Daley, M. and Moore, J. (2007) 'Mentoring Plus - plus what?', Widening Participation and Lifelong Learning 9, 2: 40-47.

Bridger, K., Shaw, J \& Moore, J. (2012). Fair Admissions to Higher Education, SPA Report. [ONLINE]. Available at http://www.spa.ac.uk/documents/Full SPA Contextual data Research Re port-Feb2012.pdf. (Accessed 16 October 2015).

Care Leavers Association. (2012) 'Accessing Further \& Higher Education'. [ONLINE]. Available at: http://www.careleavers.com/acessingeducation (Accessed 18 May 2015).

Department of Education and Skills. (2013) 'Widening Participation in Higher Education', [ONLINE]. Available at: https://www.gov.uk/government/collections/widening-participation-inhigher-education (Accessed 22 October 2014).

Department for Business, Innovation and Skills. (2014) 'National strategy for access and student success in Higher Education', [ONLINE]. Available at: https://www.gov.uk/government/uploads/system/uploads/attachment_data/f ile/299689/bis-14-516-national-strategy-for-access-and-student-success.pdf (Accessed: 18 May 2015).

Department for Business, Innovation and Skills. (2015) 'Government Policy: Higher Education participation' [ONLINE]. Available at: https://www.gov.uk/government/publications/2010-to-2015-governmentpolicy-higher-education-participation/2010-to-2015-government-policyhigher-education-participation, (Accessed 16 October 2015).

Greenhalgh, T., Seyan, K. and Boynton, P. (2004) 'Not a University type: A focus group study of social class, ethnicity and sex differences in school pupils' perception about medical school', British Medical Journal 328: 1541-1544.

Hart, D. and Williams, A. (2008) 'Putting Corporate Parenting into Practice: Developing an Effective Approach: a toolkit for councils', JKP London: National Children's Bureau. [ONLINE]. Available at: http://resources.leavingcare.org/uploads/65144764a2302008c4d440f68b91d $\underline{06 \mathrm{~d} . p d f}$

National Network for the Education of Care Leavers. (2013) 'Supporting Care Leavers in HE and FE', [ONLINE]. Available at: 
http://resources.leavingcare.org/uploads/3a60afb8d3a8935292ca5df077c69 d27.pdf (Accessed 20 October 2014).

Ofsted. (2008) 'Looked After Children - good practice in schools', [ONLINE]. Available at: http://dera.ioe.ac.uk/8180/ (Accessed 20 May 2015).

Swain, H. (2006) 'Intensive care for Non Traditional Medics', The Guardian, 4 October 2006, [ONLINE]. Available at:

http://www.theguardian.com/education/2006/oct/24/highereducation.studen $\underline{\text { ts1 }}$

Universities and College Admissions Service. (2013) 'Application Cycle: End of Cycle Report', London: UCAS. [ONLINE]. Available at:

https://www.ucas.com/sites/default/files/ucas-2013-end-of-cycle-report.pdf, (Accessed 20 May 2015). 